\title{
AdaPtaÇÃo E EFICIÊNCIA DE UM ÍNDICE DE INTEGRIDADE BIÓTICA PARA ANÁLISE DA SUSTENTABILIDADE EM FLORESTAS URBANAS
}

\author{
Thaís Graciano-Silva ${ }^{1 *}$, Kaline de Mello $^{2}$, Eliana Cardoso-Leite $^{3}$
}

\author{
${ }^{1}$ Bióloga, Universidade Federal de São Carlos (UFSCar) campus Sorocaba, PPGSGA - Programa de Pós Graduação em Sustentabilidade na Gestão \\ Ambiental. \\ ${ }^{2}$ Bióloga, Universidade de São Paulo (USP), Departamento de Ecologia, São Paulo, SP, Brasil, Laboratório de Ecologia de Paisagens e Conservação. \\ ${ }^{3}$ Bióloga, Universidade Federal de São Carlos (UFSCar) campus Sorocaba, Departamento de Ciências Ambientais, Sorocaba, SP, Brasil, PPGSGA - \\ Programa de Pós Graduação em Sustentabilidade na Gestão Ambiental. \\ *Autorpara correspondência: thagraciano@gmail.com
}

Recebido em 04 de setembro de 2017. Aceito em 18 de maio de 2018. Publicado em 20 de junho de 2018.

Resumo - Diante da complexidade de monitorar e manejar fragmentos florestais urbanos, o uso de índices é uma alternativa rápida de obter informações mensuráveis em campo e parâmetros para avaliar sua conservação. O objetivo deste estudo foi adaptar um índice de integridade biótica para Floresta Estacional Semidecidual e testar sua eficiência no diagnóstico da integridade de fragmentos urbanos. O índice é composto pelos indicadores: cobertura de serrapilheira, árvores mortas em pé, gramíneas exóticas, outras espécies exóticas, cipós, clareiras, epífitas vasculares, orquídeas, palmeiras, espécies tardias e/ou ameaçadas no dossel e no sub-bosque; aos quais foram atribuídas escalas de integridade (um a cinco pontos) e cuja somatória atribui uma classificação final de integridade dos fragmentos. Aplicou-se o índice em 23 fragmentos da cidade de Sorocaba/SP, sendo 15 deles classificados com baixa integridade e oito como integridade regular, incluindo os remanescentes em matriz urbana mais íntegros da cidade. Os resultados obtidos foram considerados satisfatórios, pois geraram diferenciações na classificação da integridade das áreas que são condizentes com o observado em campo. A maior parte dos fragmentos estudados apresentam ameaças à sua sustentabilidade, evidenciando que a maioria destas áreas carece de esforços voltados para seu manejo e conservação para que continuem a exercer suas funções ecológicas.

Palavras-chave: Sustentabilidade De Florestas Urbanas; Floresta Estacional SEmidecidual; Avallação Ecológica RAPIDA.

ADAPTACIÓN Y EFICIENCIA DE UN ÍNDICE DE INTEGRIDAD BIÓTICA PARA EL ANÁLISIS DE LA SOSTENIBILIDAD EN LOS BOSQUES

REsumen - Ante la complejidad de monitorear y manejar fragmentos forestales urbanos, el uso de índices es una alternativa rápida de obtener informaciones mensurables en el campo y parámetros para evaluar su conservación. El objetivo de este estudio fue adaptar un índice de integridad biótica para Bosque Estacional Semidecidual y probar su eficiencia en el diagnóstico de la integridad de fragmentos urbanos. El índice está compuesto por los indicadores: cobertura de hojarascas, árboles muertos de pie, gramíneas exóticas, otras especies exóticas, liana, claros, epífitas vasculares, orquídeas, palmeras, especies tardías y/o amenazadas en el dosel y en el sub-bosque; a los cuales se asignaron escalas de integridad (uno a cinco puntos) y cuya suma atribuye una clasificación final de integridad de los fragmentos. Se aplicó el índice en 23 fragmentos en la ciudad de Sorocaba, Estado de São Paulo, Brasil, 15 de ellos se clasificaron con baja integridad y ocho como integridad regular, incluyendo los remanentes en matriz urbana más íntegros de la ciudad. Los resultados obtenidos fueron considerados satisfactorios, pues generaron diferenciaciones en la clasificación de la integridad de las áreas que son condecentes con lo que se observa en el campo. La mayor parte de los fragmentos estudiados presentan amenazas a su sostenibilidad, evidenciando en la mayoría de estas áreas se necesitan esfuerzos su manejo y conservación para que continúen desempeñando sus funciones ecológicas. 
Palabras clave: Sostenibilidad De Los Bosques Urbanos; Bosque Estacional Semidecidual; Evaluación Ecológica RÁPIDA.

\section{ADAPTATION AND EFFICIENCY OF A BIOTIC INTEGRITY INDEX FOR SUSTAINABILITY ANALYSIS IN URBAN FORESTS}

Aвstract - Facing the complexity of urban forest fragments' monitoring and planning, the use of indexes is a fast alternative to obtain measurable information in the field and parameters for the evaluation of its conservation. This study aimed to adapt a biotic integrity index to Seasonal Semideciduous Forests, and to test its efficiency in evaluating urban forest fragments integrity. The index is composed of: litter coverage, standing dead trees, exotic grasses, other exotic species, lianas, gaps, orchids, palm trees, late and/or threatened species in the canopy and in the understory, to which integrity scales (one to five points) were assigned and their sum results in a final rating of the fragment's integrity. This index was applied to 23 forest fragments in the city of Sorocaba/SP, 15 of them were rated as low integrity fragments and eight as regular integrity, including the remnants in the city's most intact urban matrix. The results obtained were considered satisfactory, since they generated differentiations in the classification of the integrity of the areas that are consistent with the one observed in the field. Most of the studied fragments present threats to their sustainability, evidencing that most of those areas lack management and conservation efforts in order to keep their ecological functions.

Keywords: Sustainability OF URban Forests; SEAsonal SEMIdeCiduous Forest; Rapid Ecological Assessment.

\section{INTRODUÇÃO}

A exploração desenfreada dos recursos ambientais é uma das principais causas geradoras das alterações na qualidade da vida humana e de todas as outras espécies existentes no planeta, sendo seus efeitos nitidamente presenciados nas cidades (Rocha 2013), nas quais os processos de urbanização têm influenciado o ambiente global causando mudanças na estrutura e nos processos ecossistêmicos (Wu et al. 2017). Desta forma, as áreas urbanas se tornaram cenários de grande desafio na promoção da sustentabilidade, uma vez que causam alterações nos ecossistemas naturais (Lopes 2016) ao influenciar o clima criando ilhas de calor, gerando gases e partículas poluentes e aumentando os impactos decorrentes do efeito estufa (Buyantuyev e Wu 2010). Estes efeitos prejudiciais são decorrentes do processo rápido e massivo da urbanização, o qual gera consideráveis mudanças nos ecossistemas naturais, alterando os ciclos biogeoquímicos e hidrológicos, fragmentando habitats e levando a perda de biodiversidade (Alberti 2010, Pulighe et al. 2016).

O estudo dos ecossistemas urbanos pode elucidar as interações entre processos sociais e ecológicos que agem em escalas temporais e espaciais múltiplas e pode ajudar na compreensão da influência entre aumento populacional, crescimento econômico, uso do solo e políticas de manutenção de florestas urbanas (Dobbs et al. 2011). A proteção do meio ambiente deve ser entendida como um dos processos integrantes do desenvolvimento sustentável e não como um esforço isolado das demais ações (Libardoni et al. 2007), isto porque a estrutura e, consequentemente, a função das florestas urbanas determina a provisão de bens e serviços, sendo que quando a estrutura é alterada, pode-se alterar também as funções que maximizam o bem estar humano nas cidades (Dobbs et al. 2011).

As florestas urbanas são reconhecidas como elementos essenciais para a sustentabilidade das cidades (Steenberg et al. 2015) ao sequestrar carbono, filtrar poluentes, moderar o clima, controlar enchentes e manter a biodiversidade local (Alberti 2010). Cientes do importante papel que estas áreas desempenham, o poder público por vezes utiliza a estratégia de decretá-las como locais legalmente protegidos por acreditar que este instrumento 
de política pública será capaz de reduzir a degradação ambiental e estimular a sua conservação (Bilar e Pimentel 2015). Entretanto, para que elas estejam de fato protegidas, é necessário repensar como se dá a estruturação urbana, visando otimizar o uso dos espaços, promover maior qualidade de vida, incentivar a cultura e a diversidade social, minimizar o consumo de recursos e conservar os ecossistemas naturais que a compõe (Wu 2010).

Conhecer a qualidade da vegetação urbana e suas adaptações às mudanças ambientais é muito importante para subsidiar ações de recuperação e conservação destes remanescentes florestais (Fonseca e Carvalho 2012). Os estudos ecológicos em áreas urbanas têm focado justamente o conhecimento de sua estrutura e biodiversidade (Souza et al. 2009, Fonseca e Carvalho 2012, Coelho et al. 2016), entretanto, ainda utilizam métodos onerosos e que demandam um longo tempo de análise, sendo raros os estudos sobre dinâmica e integridade que aplicam metodologias de análise rápida (Sayre et al. 2000).

Alguns estudos propuseram o uso de índices para a análise rápida da integridade florestal, no entanto, eles têm sido elaborados para áreas de florestas tropicais relativamente grandes (Medeiros e Torezan 2012) e inseridas em paisagem florestal ou agrícola (Medeiros et al. 2015), mantendo a lacuna deste conhecimento para aplicação em florestas urbanas.

O presente estudo partiu do índice proposto por Medeiros e Torezan (2012) que é composto pelos indicadores: cobertura de serapilheira, árvores mortas em pé, cobertura de gramíneas exóticas, outras espécies exóticas, lianas, eco-unidades, epífetas vasculares (exceto orquídeas), orquídeas, figueiras (Ficus ssp), palmeiras (Euterpe edulis) e peroba rosa (Aspidosperma polyneuron), e teve como objetivo adaptá-lo para uso em área de Floresta Estacional Semidecidual no Estado de São Paulo, bem como testar sua eficiência no diagnóstico da integridade biótica de fragmentos florestais inseridos em matriz urbana. O pressuposto deste estudo é que quanto mais íntegros estes fragmentos se apresentem maior seria sua sustentabilidade, ou seja, sua capacidade de se manter ao longo do tempo.

\title{
Material e mÉtodos
}

\author{
Área de Estudo
}

O município de Sorocaba (latitude S $23^{\circ} 23^{\prime} 38^{\prime \prime}$ /longitude O 47²9’04”) localizado no interior do Estado de São Paulo apresenta população de 644.919 habitantes e abrange área territorial de $450 \mathrm{Km}^{2}$ (IBGE 2015). Sua vegetação é representada pela Floresta Estacional Semidecidual, uma das fitofisionomias do Bioma da Mata Atlântica (IBGE 2012), que apresenta clima, segundo a classificação de Köpen, do tipo Cwa (clima subtropical quente), caracterizado por inverno seco e verão quente, apresentando temperatura média de $22^{\circ} \mathrm{C}$ e pluviosidade média de $1287 \mathrm{~mm}$ por ano (CEPAGRI 2015).

Os fragmentos florestais estudados se localizam no interior da área urbana consolidada da cidade de Sorocaba e se caracterizam como parques urbanos, parques naturais municipais, áreas de preservação permanente e áreas florestadas presentes no interior dos condomínios (Figura 1), todas elas com entorno industrial (indústrias metalúrgicas, eletroeletrônicas e químicas), residencial ou comercial. 
Foram selecionados 23 fragmentos florestais inseridos em meio urbano com tamanho variando entre 0,32 e 31 ha (Figura 1). No interior de cada uma destas áreas foram estabelecidas três parcelas, de $10 \mathrm{~m}$ x $10 \mathrm{~m}$ (100 $\mathrm{m}^{2}$ ), as quais foram distribuídas por amostra aleatória (evitando sempre que possível as regiões de bordas) a fim de amostrar representativamente toda a extensão dos locais de estudo, sendo em cada parcela aplicado o Índice de Integridade Biótica - IIB (Medeiros e Torezan 2012) adaptado.

Figura 1: Localização, tamanho e classificação (PU - Parque Urbano; PNM - Parque Natural Municipal; APP - Área de Preservação Permanente; AFC - Área Florestada de Condomínio) dos 23 fragmentos florestais estudados na cidade de Sorocaba, Estado de São Paulo, Brasil.

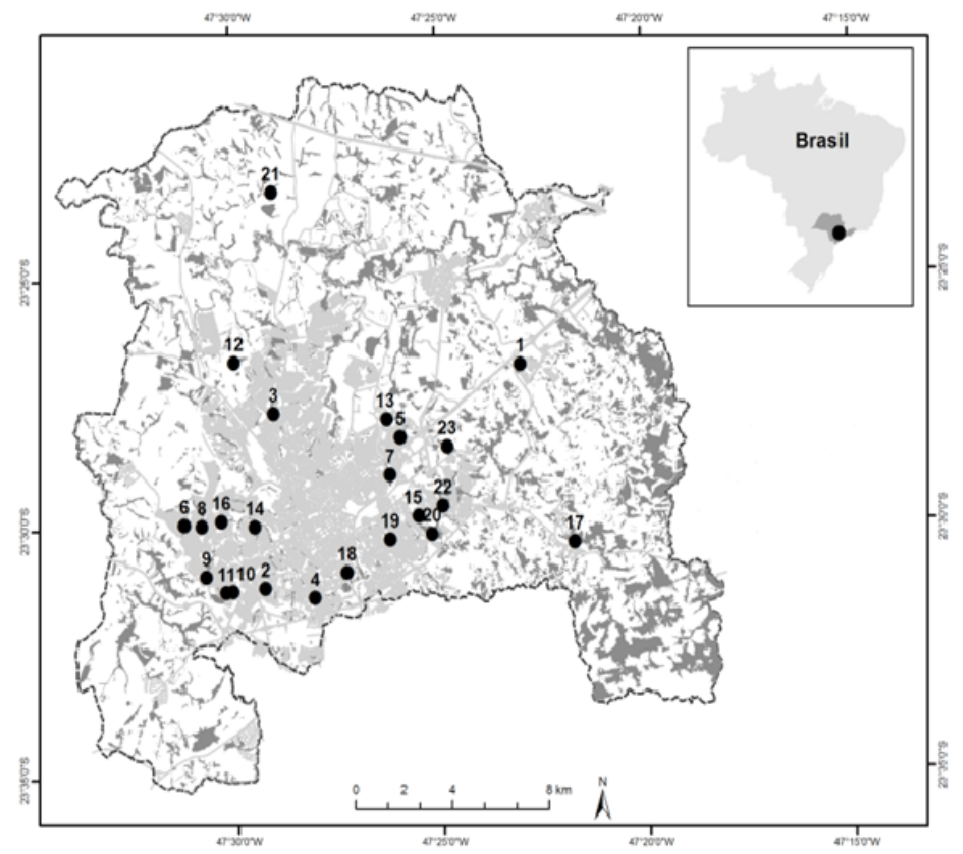

Legenda:

Malha viária
Fragmentos florestais
Limite do município de Sorocaba/SP

- Fragmentos florestais amostrados

$\mathbf{N}^{\circ}$

1 Parque Raul de Moura Bittencourt

2 Parque João Câncio Pereira - Água Vermeha

3 Parque Natural Juracy Antônio Boaro

4 Parque Carlos Alberto de Souza

5 Parque Yves Ota

6 Parque Miguel Gregório de Oliveira

7 Parque Linear Armando Pannunzio

8 Jardim Wanel Ville

9 Piazza Di Roma II (Pablo Gomes Matielli)

10 Piazza Di Roma I (Carlos David Oetterer de Almeida)

11 Condominio Villa dos Inglezes

12 Parque Pedro Paes de Almeida - Horto Municipal

13 Parque Jardim Botânico

14 Jardim Simus

15 Jardim Gonçalves

16 Parque Ouro Fino

17 Parque Brigadeiro Tobias

18 Parque da Biquinha

19 Parque Quinzinho de Barros - Zoológico

20 Parque Três Meninos

21 Parque Natural Municipal Corredores da Biodiversidade

22 Parque Natural Dr. Braulio Guedes da Silva

23 Parque Natural Chico Mendes

$\begin{array}{cc}\text { Tamanho (ha) } & \text { Classificação } \\ 2,38 & \text { PU } \\ 0,32 & \text { PNM } \\ 1,44 & \text { PNM } \\ 0,48 & \text { PU } \\ 1,00 & \text { PU } \\ 1,55 & \text { PU } \\ 2,46 & \text { APP } \\ 9,03 & \text { PU } \\ 4,72 & \text { APP } \\ 6,67 & \text { APP } \\ 2,49 & \text { AFC } \\ 12,25 & \text { PNM } \\ 1,30 & \text { PU } \\ 7,52 & \text { PU } \\ 3,78 & \text { PU } \\ 8,03 & \text { PU } \\ 2,99 & \text { PNM } \\ 2,63 & \text { PU } \\ 5,06 & \text { PU } \\ 19,16 & \text { PNM } \\ 31,00 & \text { PNM } \\ 6,23 & \text { PNM } \\ 6,26 & \text { PU }\end{array}$


Dentre as adaptações realizadas no índice original, o indicador "eco-unidades" foi substituído por "clareiras", pois no indicador original existia uma mistura de critérios utilizando desde "o tamanho das clareiras existentes" até "a altura das árvores do dossel superior". Optou-se por usar apenas as clareiras, de modo a ficar mais objetiva a sua avaliação em campo.

O indicador original "palmeiras (Euterpe edulis)" foi substituído por "Palmeiras" de quaisquer espécies, pois a ocorrência desta espécie na região de estudo, ou seja, em fragmentos de Floresta Estacional no Estado de São Paulo, atualmente é muito pequena (Albuquerque e Rodrigues 2000, Cardoso-Leite e Rodrigues, 2008, Kortz et al. 2014, Correa et al. 2014, Coelho et al. 2016).

Os indicadores "Ficus spp." e "Aspidosperma polyneuron” foram substituídos pelos indicadores "espécies tardias e/ou ameaçadas no dossel" e "espécies tardias e/ou ameaçadas no sub-bosque". Para o primeiro (dossel) foram consideradas como indicadoras as espécies Cariniana spp. (Jequitibá), Cedrela fissilis Vell., Copaifera langsdorffi Desf. , Aspidosperma polyneuron Müll.Arg. , e para o segundo (sub-bosque) foi considerada a presença de espécies das famílias Myrtaceae, Rubiaceae e Meliaceae (Trichilia). Para ambos os casos as espécies/famílias foram selecionadas a partir de estudos realizados previamente na região (Albuquerque e Rodrigues 2000, Cardoso-Leite e Rodrigues, 2008, Kortz et al. 2014, Correa et al. 2014, Coelho et al. 2016).

Para os demais indicadores, que foram mantidos como no método original, foram atribuídas novas escalas de integridade para que fossem adequadas aos padrões esperados para fragmentos inseridos em habitat de Floresta Estacional Semidecidual. A aplicação do índice se deu com a utilização de um guia de campo estruturado (Tabela 1) que orientou a atribuição de notas conforme a escala de integridade observada em cada parcela.

Tabela 1: Guia utilizado em campo para análise do IIB (modificado e adaptado de Medeiros e Torezan 2012) e atribuição de notas para cada parcela. ${ }^{1}$ Considerar o número de indivíduos; ${ }^{2}$ Considerar o número de espécies; ${ }^{3}$ Considerar indivíduos de Cariniana spp. (Jequitibá), Cedrela fissilis Vell.(Cedro), Copaifera langsdorffi Desf. (Copaíba), Aspidosperma polyneuron Müll.Arg. (Peroba-rosa); ${ }^{4}$ Considerar indivíduos das famílias Rubiaceae, Myrtaceae e Meliaceae (Trichillia sp).

\begin{tabular}{|c|c|c|c|c|c|}
\hline \multirow{2}{*}{ Variável } & \multicolumn{5}{|c|}{ Escala de Integridade } \\
\hline & 1 & 2 & 3 & 4 & 5 \\
\hline Cobertura de Serrapilheira & $\begin{array}{l}\text { Ausente / Solo } \\
\text { exposto }\end{array}$ & $25 \%$ & $50 \%$ & $75 \%$ & $100 \%$ \\
\hline Árvores Mortas em Pé ${ }^{1}$ & $>3$ & 3 & 2 & 1 & Ausente \\
\hline $\begin{array}{l}\text { Cobertura de Gramíneas Exó- } \\
\text { ticas }\end{array}$ & $>50 \%$ & $25-50 \%$ & Até $25 \%$ & Até $10 \%$ & Ausente \\
\hline Outras Espécies Exóticas ${ }^{2}$ & $>3$ & 3 & 2 & 1 & Ausente \\
\hline Cipós & $\begin{array}{l}\text { >3 emaranha- } \\
\text { dos (Somente } \\
\text { finas) }\end{array}$ & $\begin{array}{l}2 \text { emaranhados } \\
\text { (Somente finas) }\end{array}$ & $\begin{array}{c}\text { Ausente ou } 1 \\
\text { emaranhado } \\
\text { (Somente finas) }\end{array}$ & $\begin{array}{c}\text { Grossas } \\
\text { (diam. }>4 \mathrm{~cm}) \\
\text { e finas (emar.) }\end{array}$ & $\begin{array}{c}\text { Lenhosas } \\
\text { grossas } \\
\text { (diam. }>4 \mathrm{~cm})\end{array}$ \\
\hline Clareiras & $\begin{array}{c}>50 \% \text { ocupada } \\
\text { por clareiras }\end{array}$ & $\begin{array}{c}25 \text { a } 50 \% \\
\text { ocupada por } \\
\text { clareiras }\end{array}$ & $\begin{array}{c}\text { Até } 25 \% \text { ocu- } \\
\text { pada por cla- } \\
\text { reiras }\end{array}$ & $\begin{array}{c}\text { Até } 10 \% \\
\text { ocupada por } \\
\text { clareiras }\end{array}$ & Ausente \\
\hline Epífitas Vasculares ${ }^{1}$ & Ausente & 1 & $2-4$ & $5-9$ & $>10$ \\
\hline Orquídeas ${ }^{1}$ & Ausente & 1 & 2 & 3 & $>3$ \\
\hline Palmeiras ${ }^{1}$ & Ausente & $\begin{array}{l}\text { Somente indi- } \\
\text { víduos regene- } \\
\text { rantes }\end{array}$ & $\begin{array}{l}1 \text { indivíduo } \\
\text { adulto }\end{array}$ & $\begin{array}{l}2 \text { indivíduos } \\
\text { adultos }\end{array}$ & $\begin{array}{l}>2 \text { indivíduos } \\
\text { adultos }\end{array}$ \\
\hline $\begin{array}{l}\text { Espécies Tardias e/ou Ameaça- } \\
\text { das no Dossel } 2,3\end{array}$ & Ausente & 1 & 2 & 3 & 4 \\
\hline $\begin{array}{l}\text { Espécies Tardias e/ou Ameaça- } \\
\text { das no Sub-bosque }\end{array}$ & Ausente & 1 & 2 & 3 & 4 ou mais \\
\hline
\end{tabular}


O IIB é composto por 11 indicadores, aos quais foram atribuídas escalas de integridades que variam de um a cinco pontos e cuja somatória atribui uma classificação final relativa à integridade ambiental das parcelas analisadas. Como em cada área foram delimitadas três parcelas, a obtenção da nota final de um fragmento (IIB) se deu pela média aritmética das notas obtidas para cada parcela, podendo sua integridade ser classificada como: "muito baixa" (11 a 19,9 pontos), "baixa" (20 a 29,9 pontos), "regular" (30 a 39,9 pontos), "boa" (40 a 49,9 pontos) ou "excelente" (50 a 55 pontos). Para determinação do $\mathrm{N}$ amostral seguiu-se a proposta do método original (Medeiros e Torezan, 2012) que utilizou 3 pontos de observação, independente do tamanho da área.

Neste estudo, considerou-se como áreas possuidoras de sustentabilidade, ou seja, locais com capacidade de se manter a longo prazo, aquelas que obtivessem a classificação de "boa" ou "excelente" quanto a sua integridade biótica ou que atingissem no mínimo $60 \%$ do valor máximo possível para o IIB.

Embora o valor do IBB seja determinado pela média entre os valores encontrados na soma dos indicadores de cada unidade amostral (pontos de observação ou parcelas), no presente estudo foi importante analisar os indicadores um a um, de modo a elucidar quais deles melhor refletiriam "integridade biótica" de florestas fragmentadas em matriz urbanizada, uma vez que o objetivo do presente estudo foi adaptar o IBB original descrito por Medeiros \& Torezan (2012). Para tal, foram elaborados gráficos de dispersão cruzando a nota do IIB atribuída a cada fragmento com a nota da escala de integridade (um a cinco - variação que representa o estado de cada indicador) atribuída para cada uma das 69 parcelas utilizadas neste estudo, sendo esta análise realizada individualmente para cada um dos indicadores.

\section{Adaptação do Índice - Áreas de Referência}

Para testar os parâmetros adotados após as alterações e a capacidade da nota final de fornecer um diagnóstico condizente com a realidade, o índice foi aplicado em duas áreas de referência antes de ser aplicado nos 23 fragmentos selecionados. A aplicação do índice proposto previamente nestas áreas se deu a fim de avaliar se ele era capaz de traduzir os melhores e piores cenários para cada indicador, sendo para isso analisado se as notas obtidas no IIB são concordantes com a realidade relatada em estudos publicados sobre estes locais.

O remanescente florestal escolhido para servir como "referência de área bem conservada" apresenta 2.273,60 ha e está localizado no interior da Floresta Nacional de Ipanema (S 2325'44”/O 47³7’24”), uma Unidade de Conservação de Uso Sustentável cujo território legal ocupa os municípios de Iperó, Araçoiaba da Serra e Capela do Alto. Apesar de não estar na mesma cidade que os demais fragmentos analisados, este local foi selecionado por ser o fragmento de Floresta Estacional Semidecidual mais conservado da região, por estar relativamente próximo dos outros fragmentos amostrados (cerca de $8 \mathrm{~km}$ ) e por ser um local no qual há diversas pesquisas que auxiliaram na verificação da adequação do índice adaptado.

O remanescente selecionado para servir como "referência de área degradada" possui 7,05 ha e localiza-se

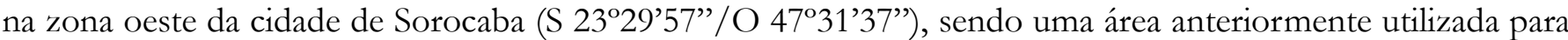
pastagem e que após 15 anos de abandono recuperou sua cobertura florestal por meio de regeneração natural.

\section{REsultados}

Para o fragmento "referência de área bem conservada", obteve-se a nota de 40 pontos o que o caracteriza 
como um fragmento de boa integridade biótica, enquanto o fragmento "referência de área degradada" obteve nota de 19,34 pontos, identificando-o como um fragmento de integridade biótica muito baixa. Quando aplicado o índice nos 23 fragmentos selecionados, as notas obtidas variaram de 22,34 a 35,34, sendo oito áreas classificadas com integridade regular e 15 com integridade baixa (Tabela 2).

Tabela 2: Fragmentos analisados, a nota final obtida (Nota IIB) e a sua classificação conforme o IIB. *Áreas cuja nota do IIB é superior à $60 \%$ do índice.

\begin{tabular}{lcc}
\hline \multicolumn{1}{c}{ Fragmentos } & Nota IIB & Classificação IIB \\
\hline Parque Raul de Moura Bittencourt & 22,34 & Baixa \\
Parque João Câncio Pereira - Água Vermelha & 23,67 & Baixa \\
Parque Natural Juracy Antônio Boaro & 23,67 & Baixa \\
Parque Carlos Alberto de Souza & 25,34 & Baixa \\
Parque Yves Ota & 26,00 & Baixa \\
Parque Miguel Gregório de Oliveira & 26,00 & Baixa \\
Parque Linear Armando Pannunzio & 26,67 & Baixa \\
Jardim Wanel Ville & 28,00 & Baixa \\
Piazza Di Roma II (Pablo Gomes Matielli) & 28,67 & Baixa \\
Piazza Di Roma I (Carlos David Oetterer de Almeida) & 28,67 & Baixa \\
Condomínio Villa dos Inglezes & 29,00 & Baixa \\
Parque Pedro Paes de Almeida - Horto Municipal & 29,00 & Baixa \\
Parque Jardim Botânico & 29,33 & Baixa \\
Jardim Simus & 29,34 & Baixa \\
Jardim Gonçalves & 29,67 & Baixa \\
Parque Ouro Fino & 30,34 & Regular \\
Parque Brigadeiro Tobias & 30,66 & Regular \\
Parque da Biquinha & 31,00 & Regular \\
Parque Quinzinho de Barros - Zoológico & 32,67 & Regular \\
Parque Três Meninos & $33,34^{*}$ & Regular \\
Parque Natural Municipal Corredores da Biodiversidade & $33,34^{*}$ & Regular \\
Parque Natural Dr. Braulio Guedes da Silva & $35,34 *$ & Regular \\
Parque Natural Chico Mendes & $35,34 *$ & Regular \\
\hline
\end{tabular}

Destaca-se que dentre os fragmentos com integridade regular, quatro áreas obtiveram notas maiores que 33 pontos (Tabela 2), o que representa mais de 60\% da nota máxima possível na aplicação do índice e aponta que a maioria dos indicadores utilizados se faz presente, em suas melhores formas, nestes locais.

A Figura 2 apresenta como cada indicador se comportou no diagnóstico das áreas estudadas e como se deu a variação das classes de integridade elaboradas nas 69 parcelas estabelecidas no interior dos fragmentos analisados.

Figura 2: Gráficos de dispersão dos atributos, relacionados aos indicadores A) cobertura de serapilheira; B) árvores mortas em pé; C) cobertura de gramíneas exóticas; D) outras espécies exóticas; E) cipós; F) clareiras; G) epífitas vasculares; H) orquídeas; I) palmeiras; J) espécies tardias e/ou ameaçadas no dossel; K) espécies tardias e/ou ameaçadas no sub-bosque, encontrado nas parcelas realizadas no interior dos 23 fragmentos analisados. 
A

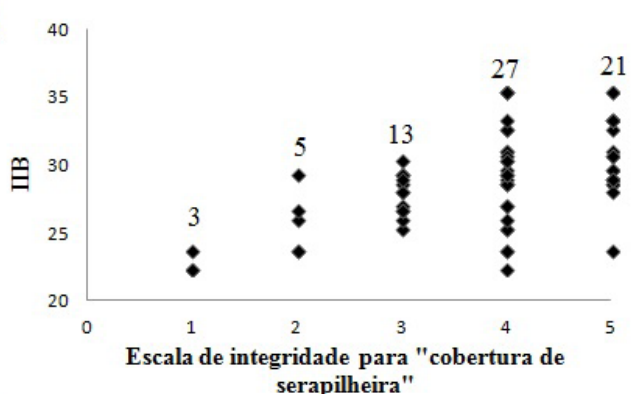

C

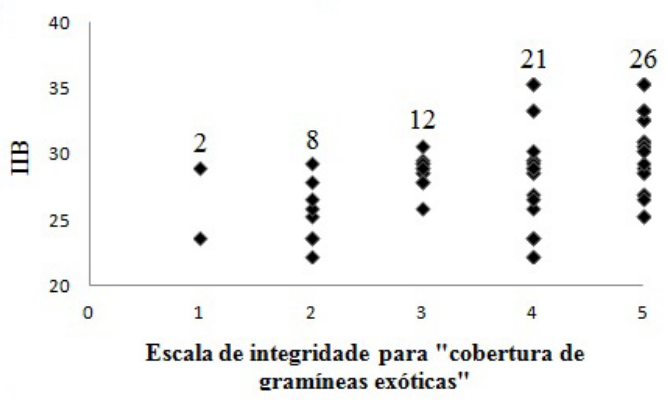

E

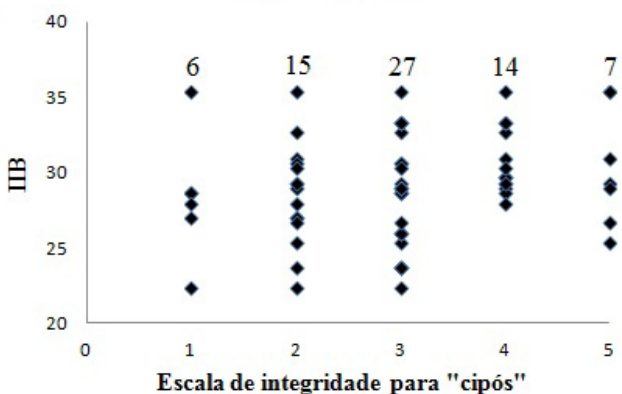

G
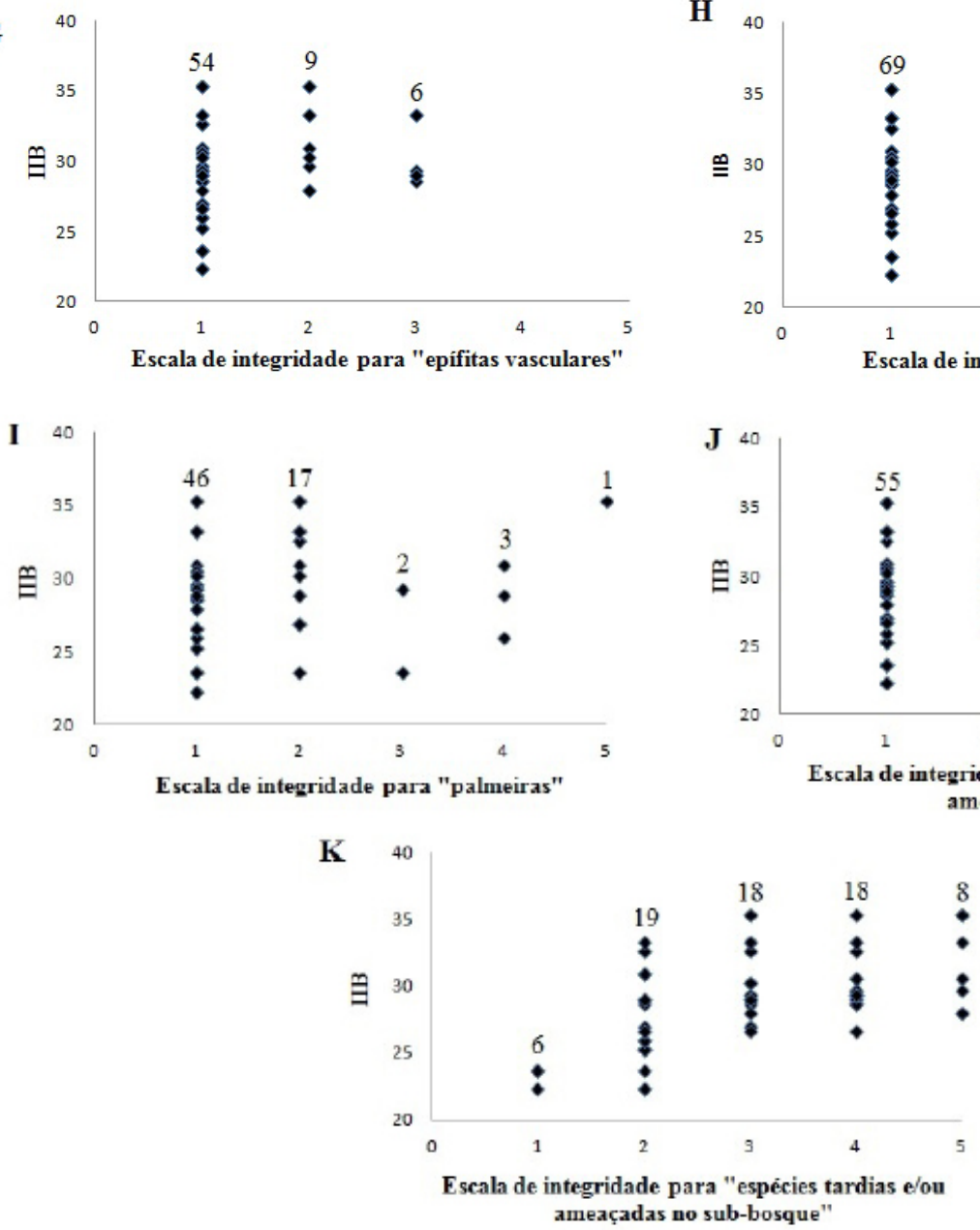

GAIA SCIENTIA (2018). VOLUME 12(2): 60-75

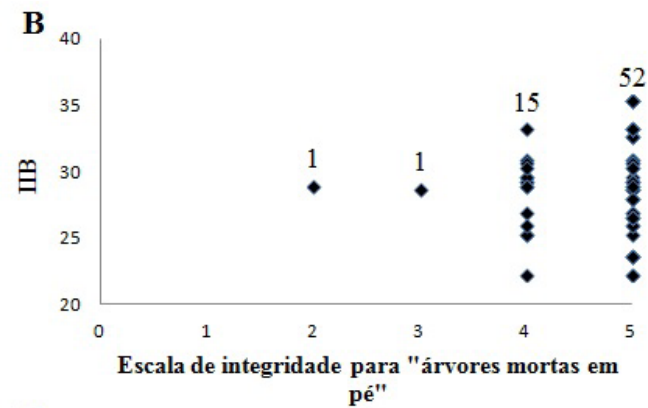

D
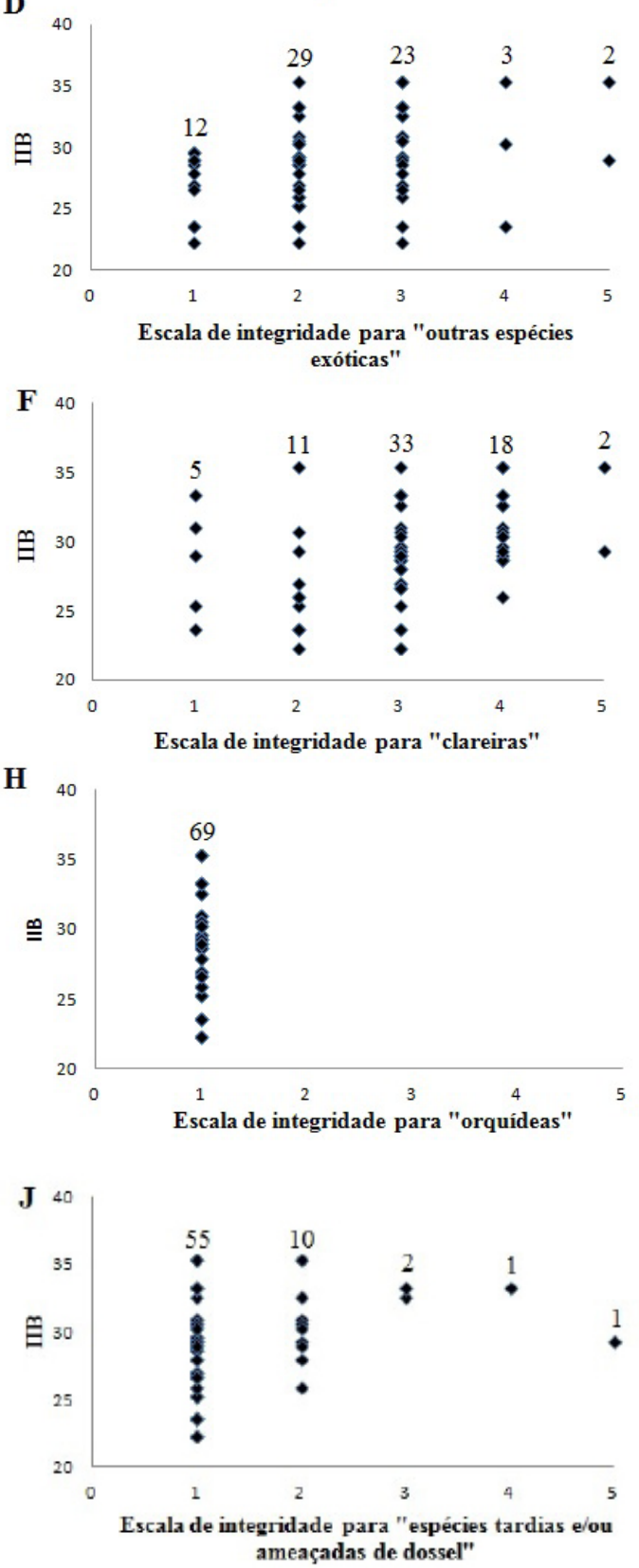
meaçadas de dossel" 


\section{Discussão}

\section{Análise dos Indicadores Utilizados no Índice}

Para o indicador "cobertura de serapilheira" (Figura 2A), pode-se constatar sua grande quantidade nas parcelas analisadas, estando presente em 100\% da área em 21 parcelas e presente em até 75\% em 27 parcelas. Este resultado condiz com o que é costumeiramente encontrado em Florestas Estacionais Semideciduais (Scoriza e Piña-Rodrigues 2013), uma vez que fragmentos urbanos apresentam-se, em sua maioria, em fases iniciais e médias de sucessão, nas quais o volume de material orgânico depositado no solo tende a ser maior quando comparado às demais fases sucessionais por conta do ciclo natural das espécies pioneiras (Dickow et al. 2012).

O indicador "árvores mortas em pé” (Figura 2B) estava ausente em 52 parcelas e presente, com um organismo, em apenas 15 das parcelas analisadas. A taxa de mortalidade está diretamente ligada às alterações abruptas nas condições microclimáticas do remanescente, assim, acredita-se que o fato dos remanescentes estarem inseridos em contexto urbano faz com que eles estejam sujeitos ao aumento da velocidade dos ventos, na umidade do solo e ar e elevação da temperatura, ultrapassando a tolerância fisiológica de muitos organismos arbóreos que acabam abortando suas folhas e morrendo em pé (Laurance e Vasconcelos 2009).

Com relação ao indicador "cobertura de gramíneas exóticas" (Figura 2C), em 26 parcelas ele estava ausente e em 21 ocupava até $10 \%$ da área amostrada. A concentração nestas escalas de integridade pode ser um indicativo da estruturação e sucessão ecológica já estabelecida, ocorrendo nestes locais espécies botânicas que acabam por inibir a ocorrência de organismos invasores e pioneiros como as gramíneas exóticas (Dias 2011).

O indicador "outras espécies exóticas" (Figura 2D) se apresentou com duas espécies em 23 parcelas e com três espécies em 29 parcelas, tal fato indica que em matriz urbana a introdução desses organismos tende a ser elevada devido o contato com as atividades antrópicas locais. O manejo destas espécies é necessário, pois elas possuem facilidade de adaptação e dispersão nas áreas em que se estabelecem, atuando como barreira para a regeneração natural e recrutamento de plântulas de espécies nativas (Dias 2011).

Em relação ao indicador "cipós" (Figura 2E) foram retratados organismos em todas as escalas de integridade descritas na guia de campo. A presença de cipós tanto em forma de emaranhados quanto no estágio lenhoso pode indicar remanescentes de idades e estádios sucessionais distintos, uma vez que a ocorrência de lianas lenhosas de grande diâmetro indica áreas de floresta madura e bem conservada, já a sua presença com pequeno diâmetro indica áreas de floresta em estágio sucessional intermediário ou jovem, e consequentemente mais perturbada (Castello et al. 2016).

No que se refere ao indicador "clareira" (Figura 2F), em 33 parcelas elas estavam presentes ocupando até $25 \%$ da área e em 18 parcelas ocupavam até 10\% da área. Essa proporção de abertura pode ser considerada elevada diante do tamanho das parcelas, entretanto, não gerou modificações internas relevantes, uma vez que estas aberturas podem ser facilmente recobertas pelo crescimento lateral de espécies clímax ou pelo rápido crescimento de arbustos já estabelecidos, amenizando a intensidade de luz que chega até o solo sem gerar grandes alterações na composição do sub-bosque (Santos 2005).

Para o indicador "epífitas vasculares" (Figura 2G), observou-se que em 54 parcelas estes organismos estavam ausentes, tendo sido registrados no máximo de dois a quatro organismos por local amostrado (6 parcelas), tal fato pode indicar que os fragmentos estão sujeitos a entrada de ventos e menor umidade relativa do 
ar, condições que tornam a ocorrência destes organismos mais restrita. As epífitas vasculares são encontradas em maior quantidade nas florestas em estágios sucessionais médios e menos observadas naquelas em estágio inicial, o que corrobora os resultados aqui encontrados, uma vez que as florestas urbanas estudadas apresentam características de florestas iniciais (Kersten e Kuniyoshi 2008).

Mesmo não tendo sido amostradas epífitas na maioria das parcelas, não seria interessante retirar este indicador do índice, pois sua ausência indica efetivamente a baixa integridade destas florestas; no entanto, é preciso rever a quantidade de organismos atribuídos a cada escala de integridade, já que em contextos urbanos é esperada a ocorrência de um número menor destes organismos.

Em nenhuma das parcelas analisadas foi encontrado o indicador "orquídeas" (Figura 2H), tal fato é atribuído a grande exigência microclimática destes organismos que, possivelmente, não é satisfeita pelas condições presentes em fragmentos urbanos. Diante deste resultado e por serem estes organismos vasculares epífitos com conhecido papel de indicador ambiental, sugere-se sua fusão ao indicador "epífitas vasculares".

Quanto ao indicador "palmeiras" (Figura 2I) foi possível constatar que na maioria das vezes (46 parcelas) estes organismos estavam ausentes ou presentes apenas como indivíduos regenerantes (17 parcelas). Nos fragmentos que apresentaram parcelas com ausência total destes indivíduos podem não estar chegando sementes devido ao seu isolamento na paisagem, uma vez que a principal forma de dispersão das palmeiras é pela ornitocoria (Salm et al. 2011); e naquelas onde encontrou-se plântulas, mas a inexistência de organismos na fase adulta acredita-se que pode estar havendo predação das mudas por animais domésticos, sua retirada para plantio em outros locais ou capina de sub-bosque.

A não especificação de quais espécies de palmeiras foram consideradas neste indicador pode ter enfraquecido a detecção da integridade. Desta forma, seria interessante identificar as espécies amostradas para verificar se realmente são espécies nativas, pois na área urbana podem aparecer espécies exóticas utilizadas na arborização urbana. A identificação das espécies registradas também seria importante para saber se são espécies tardias, as quais poderiam indicar uma maior integridade da área.

Considerando que o indicador "espécies tardias ou ameaçadas de dossel" (Figura 2F) envolveu a seleção de espécies amostradas em levantamentos fitossociológicos realizados na região estudada, a baixa ocorrência das mesmas no dossel pode indicar que as condições destas florestas não são adequadas para a germinação, estabelecimento e recrutamento das espécies arbóreas tardias, as quais necessitam de sombreamento moderado e condições especiais para que suas plântulas não tenham o crescimento inibido por espécies pioneiras (Maciel et al. 2003). Espécies tardias, como Aspidosperma polyneuron, Cariniana spp., Cedrela fissilis e Copaifera langsdorffii, têm maior necessidade de nichos ecológicos especializados, o que torna sua ocorrência mais rara que a das espécies colonizadoras iniciais por estarem vinculadas às condições físicas e ecológicas prévias proporcionadas pelo nível sucessional local (Magurran 2006).

Para o indicador "espécies tardias e/ou ameaçadas no sub-bosque" (Figura 2G) percebe-se que a ausência de espécies de Rubiaceae, Myrtaceae ou Meliaceae ocorreu em parcelas cuja porcentagem de abertura de clareiras era elevada (acima de $25 \%$ da parcela) ou naquelas que haviam passado por um manejo de retirada de subbosque e serapilheira. A grande maioria das espécies de Myrtaceae e Rubiaceae de estratos inferiores e médios de florestas tropicais são espécies tardias típicas de sombra, sendo que o aumento da luz nas bordas ou clareiras promove a diminuição de sua frequência (Martini et al. 2008).

Os indicadores cuja pontuação variou bastante entre as parcelas foram muito úteis para compor o 
índice, em especial destaca-se "cipó", "clareiras" e "espécies tardias e/ou ameaçadas no sub-bosque". Já os indicadores cuja pontuação pouco variou entre as parcelas, como "árvores mortas em pé" e "epífitas vasculares", proporcionaram alterações discretas na diferenciação de notas da integridade entre os fragmentos, no entanto, agregaram informações relevantes, uma vez que sua presença em poucas áreas e parcelas as diferenciou do conjunto geral (Tabela 2/Figura 2).

\section{Áreas de Referência}

O fragmento selecionado como "área de referência degradada" é uma antiga área de pastagem abandonada que teve sua vegetação recuperada naturalmente, sendo possível constatar abundância de espécies exóticas, destacando-se a grande quantidade de Leucaena sp. e Brachiaria sp. que tomam sua área quase que por completo. Hoje rodeada por avenidas e áreas de pasto, esta área sofre com os impactos provenientes da sua vizinhança, condição que se refletiu na aplicação do índice desenvolvido no local.

Ao analisar o perfil encontrado, nota-se ausência de "epífitas vasculares", "orquídeas", "palmeiras", "espécies tardias e/ou ameaçadas no dossel" e de "espécies tardias e/ou ameaçadas no sub-bosque"; enquanto era muito presente a "cobertura de gramíneas exóticas", de "outras espécies exóticas" e de "clareiras". Os indicadores "cobertura de serapilheira", "árvores mortas em pé" e "cipós", foram pouco encontrados nas parcelas desta área.

Já o fragmento selecionado como "referência de área bem conservada" encontra-se na zona primitiva de uma unidade de conservação, circunstância que acaba conferindo maior proteção aos elementos naturais que nela ocorrem; entretanto, ela também está submentida a pressões provenientes de sua matriz, a qual é composta por assentamentos de agricultura familiar, áreas degradadas, pastagens, antigas jazidas de ferro e eucaliptais, separando-se de todos estes usos do solo por aceiros e estradas de terra (Ministério do Meio Ambiente 2012). Acredita-se que esta condição do entorno acaba gerando certo impacto no fragmento e impede que este obtenha melhor classificação quanto à sua integridade biótica.

Quando analisado o perfil encontrado, nota-se um número reduzido de "árvores mortas em pé”, "gramíneas exóticas" e "presença de espécies exóticas", sendo bastante presente a "cobertura de serapilheira", a presença de indivíduos adultos de "palmeiras" e das "espécies tardias e/ou ameaçadas de sub-bosque". Os indicadores "cipós" se faziam presentes em formatos lenhosos, enquanto as "clareiras" se faziam presentes em tamanhos diminutos. Os indicadores "epífitas vasculares", "orquídeas" e "espécies tardias e/ou ameaçadas de dossel”, foram pouco encontrados nas parcelas.

No trabalho realizado por Medeiros e Torezan (2012), não houve uma referência de área degradada, porém, o Parque Estadual Mata dos Godoy, utilizado como referência de área bem conservada, foi classificado com integridade biótica excelente, sendo o único local, dentre os analisados pelos autores, que alcançou esta classificação. O parque em questão é considerado como o melhor remanescente da região onde o estudo foi realizado, além de ter sido apontado como um local de alta prioridade para a conservação da biodiversidade pelo painel de especialistas do Ministério Brasileiro do Meio Ambiente (Medeiros e Torezan, 2012). Assim, entendese que para atribuição de integridade excelente a uma área é necessário que ela atenda criteriosamente aos indicadores que compõe o índice criado, sendo dificilmente encontrado para fragmentos inseridos em contextos urbanos. 
O resultado encontrado corrobora a escolha dos indicadores que compõe o índice, uma vez que o potencial das duas áreas de referência já era conhecido pelo levantamento realizado por outros projetos ambientais desenvolvidos previamente nestes locais e pelo histórico regional de ocupação e uso do entorno. Desta forma, considerou-se o valor do IIB obtido condizente com as condições reais encontradas nas áreas, optando-se por manter os atributos atrelados a cada escala de integridade utilizada no guia de campo, bem como a classificação final de atribuição de nota do índice elaborado.

Fragmentos Urbanos

A Tabela 2 e a Figura 2 evidenciam que os indicadores que mais contribuíram para a nota dos fragmentos de baixa integridade foram ocorrência de espécies exóticas e de emaranhados de cipós, enquanto estiveram ausentes ou escassas as epífitas vasculares, as palmeiras e principalmente as espécies tardias e/ou ameaçadas de dossel. Diante do observado, atribui-se a grande ocorrência de cipós ao ambiente mais degradado, cujas espécies presentes não são capazes de fechar o dossel quando há abertura de clareiras, deixando espaço para que se dê a formação de emaranhados (Castello et al. 2016). Já para a grande quantidade de espécies exóticas, atribui-se sua ocorrência justamente ao contato com áreas antropizadas, nas quais sua introdução pode se dar pelo plantio direto de mudas na borda destes fragmentos ou pela dispersão de espécies usadas na arborização e jardinagem de ruas e casas (McKinney 2006, Fonseca e Carvalho 2012).

Também é possível perceber que os indicadores que contribuíram para a nota dos fragmentos de integridade regular (as melhores áreas encontradas) são justamente a presença de palmeiras e de espécies tardias e/ou ameaçadas no dossel, destacando-se ainda o fato de que, na maior parte dos casos, a nenhum dos outros indicadores era atribuída uma nota muito baixa dentro do quesito analisado (Tabela 2/Figura 2).

A priori, nenhuma das áreas foi considerada como apresentando sustentabilidade, uma vez que nenhuma delas obteve valor do IBB igual ou maior de 40 pontos (integridade boa ou excelente); no entanto, quatro áreas apresentaram índice integridade igual ou maior a $60 \%$ do total possível para o índice, sendo elas o "Parque Três Meninos", "Parque Natural Dr. Braulio Guedes da Silva", "Parque Natural Chico Mendes" e o "Parque Natural Municipal Corredores da Biodiversidade". Dentre as áreas citadas, as três primeiras são consideradas Parques Naturais, porém apesar de sua designação não constituem Unidades de Conservação (Brasil 2000) sendo somente o "Parque Natural Municipal Corredores da Biodiversidade" uma Unidade de Conservação Municipal de fato. Diante desta realidade, o poder público deveria refletir sobre a possibilidade de proteger também estas três primeiras áreas transformando-as em Unidades de Conservação, a fim de garantir normas e regras para sua utilização e minimizar o impacto sobre as mesmas.

Destaca-se ainda que o "Parque Ouro Fino", o "Parque Brigadeiro Tobias", o "Parque da Biquinha" e o "Parque Quinzinho de Barros" apresentam grande potencial para conservação, podendo apresentar melhora nas suas integridades caso sejam adotadas técnicas de manejo como, por exemplo, a erradicação de espécies exóticas (Brancalion et al. 2012), enriquecimento com espécies nativas (Simberloff et al. 2011) e o controle dos fatores externos de perturbação (deposição de resíduos sólidos e fogo).

Comparando os resultados obtidos com os de Medeiros e Torezan (2012), selecionando apenas as áreas que apresentam mesma escala de tamanho e contexto de inserção com os aqui analisados, foi possível perceber que para nove fragmentos com tamanho entre 2 e 25 ha os valores obtidos também oscilaram entre integridade 
baixa (três áreas) e regular (cinco áreas), sendo apenas um fragmento caracterizado com boa integridade. Esta semelhança entre os resultados obtidos nos dois trabalhos indica que para fragmentos pequenos e com entorno urbano, como os estudados, dificilmente deverão ser registrados valores altos de integridade, o que evidencia que a maioria dos fragmentos urbanos só conseguirão se sustentar a longo prazo diante de intervenções de manejo por parte do poder público.

\section{Conclusão}

As alterações propostas no método original se mostram eficientes no diagnóstico da integridade de fragmentos florestais inseridos em matriz urbana, uma vez que conseguiram traduzir numericamente as condições encontradas em campo. Considerou-se a escolha dos indicadores e a seleção de suas classes de atributos adequadas às situações encontradas nos fragmentos, na medida em que a maior parte dos indicadores foi bem representada no diagnóstico das parcelas. Entretanto, foram constatadas algumas carências de classificação diante das condições observadas em campo que devem ser alteradas para maior refinamento do índice, como a identificação das espécies ou gêneros para o indicador "palmeiras" e o refinamento do indicador "epífitas vasculares" com a inclusão do indicador "orquídeas" e a readequação de suas classes para uso específico em florestas urbanas. Destaca-se ainda que a inclusão do indicador “espécies tardias e/ou ameaçadas”, especialmente do sub-bosque, foi muito importante, pois contribuiu decisivamente para a eficácia do índice. Estas adequações não poderiam ter sido feitas anteriormente, e testadas nas duas áreas de referência, pois estas apresentavam apenas as condições extremas de "integridade biótica" para fragmentos florestais na região. Por isso foi necessário aplicar o índice adaptado a uma gama maior de fragmentos florestais com variação de tamanho, todos inseridos em matriz urbana.

O diagnóstico realizado pela aplicação do IIB foi capaz de indicar o potencial de manutenção das áreas estudadas, além de fornecer informações importantes sobre o seu desenvolvimento e destacar onde se faz necessário que sejam despendidos mais esforços para aumentar a integridade biótica através do manejo e conservação. Assim, constatou-se que a grande maioria (82,6\%) dos fragmentos florestais estudados não apresenta sustentabilidade a longo prazo, sendo necessário que o poder público municipal dedique maior atenção a estas florestas urbanas que, sem um manejo adequado, podem apresentar problemas para se manterem por não apresentarem integridade biótica adequada.

\section{REFERÊNCIAS}

Alberti M. 2010. Maintaining ecological integrity and sustaining ecosystem function in urban áreas. Current Opinion in Environmental Sustainability, (2): 78-184.

Albuquerque GB, Rodrigues RR. 2000. A vegetação do Morro de Araçoiaba, Floresta Nacional de Ipanema, Iperó (SP). Scientia Forestalis, (58): 145-159.

Bilar ABC, Pimentel RMM. 2015. Governança ambiental para o desenvolvimento sustentável em uma unidade de conservação no semiárido nordestino: desafios e perspectivas. Gaia Scientia, 10(3): 19-25. 
Brancalion PHS, Viani RAG, Rodrigues RR, César RG. 2012. Estratégias para auxiliar na conservação de florestas tropicais secundárias inseridas em paisagens alteradas. Boletim do Museu Paraense Emílio Goeldi. Ciências Naturais, 7(3): 219-234.

Brasil. 2000. Lei $\mathrm{n}^{\circ} 9.985$, de 18 de Julho de 2000. Sistema Nacional de Unidades de Conservação da Natureza, Brasília, 200p.

Buyantuyev A, Wu J. 2010. Urban heat islands and landscape heterogeneity: linking spatiotemporal variations in surface temperatures to land-cover and socioeconomic patterns. Landscape Ecology, 1(25): 17-33.

Cardoso-Leite E, Rodrigues RR. 2008. Fitossociologia e caracterização sucessional de um fragmento de Floresta Estacional no Sudeste do Brasil. Revista Árvore, 32(3): 583-595.

Castello ACD, Coelho S, Cardoso-Leite E. 2016. Lianas, tree ferns and understory species: indicators of conservation status in the Brazilian Atlantic Rainforest remnants, southeastern Brazil. Brazilian Journal of Biology, 77(2): 213-226.

CEPAGRI - Centro de Pesquisas Meteorológicas e Climáticas Aplicadas a Agricultura/UNICAMP. 2015. Clima dos Municípios Paulistas. Disponível em: http://www.cpa.unicamp.br/outras-informacoes/clima muni_584.html Acesso em: 10 jan. 2016.

Coelho S, Cardoso-Leite E, Castello ACD. 2016. Composição florística e caracterização sucessional como subsídio para conservação e manejo do PNMCBio, Sorocaba - SP. Ciência Florestal, 26(1): 331-344.

Corrêa LS, Cardoso-Leite E, Castello ACD, Coelho S, Kortz AR, Villela FNJ, Koch I. 2014. Estrutura, composição florística e caracterização sucessional em remanescente de Floresta Estacional Semidecidual no sudeste do Brasil. Revista Árvore, 38(5): 799-809.

Dias J. 2011. Espécies invasoras em sítios de restauração florestal de floresta estacional. 2011. Dissertação (Mestrado em Ciências Biológicas) - Universidade Estadual de Londrina, UEL: Londrina.

Dickow KMC, Marques R, Pinto CB, Höfer H. 2012. Produção de serapilheira em diferentes fases sucessionais de uma floresta subtropical secundária, em Antonina, PR. Cerne, 18(1): 75 - 86.

Dobbs C, Escobedo FJ, Zipperer WC. 2011. A framework for developing urban forest ecosystem services and goods indicators. Landscape and Urban Planning, 99: 196 - 206.

Fonseca CR, Carvalho FA. 2012. Aspectos florísticos e fitossociológicos da comunidade arbórea de um fragmento urbano de Floresta Atlântica (Juiz de Fora, MG, Brasil). Bioscience Journal, 28(5): 820 - 832.

IBGE - INSTITUTO BRASILEIRO DE GEOGRAFIA E ESTATÍSTICA. 2015. Cidade de Sorocaba. Disponível em: http://www.cidades.ibge.gov.br/xtras/perfil.php?lang=\&codmun $=355220 \&$ search=saopaulo|Sorocaba Acesso em: 20 dez. 2015.

IBGE - INSTITUTO BRASILEIRO DE GEOGRAFIA E ESTATÍSTICA. 2012. Manual técnico da vegetação brasileira. Manuais Técnicos em Geociências, 271p. 
Kersten RA, Kuniyoshi YS. 2008. Conservação das florestas na Bacia do Alto Iguaçu, Paraná - Avaliação da comunidade de epífitas vasculares em diferentes estágios serais. Floresta, 39(1): 51 - 66.

Kortz AR, Coelho S, Castello ACD, Corrêa LS, Cardoso-Leite E, Koch I. 2014. Wood vegetation in Atlantic rain Forest remnants in Sorocaba (São Paulo, Brazil). Check List, 10(2): 344-354.

Laurance WF, Vasconcelos HL. 2009. Consequências ecológicas da fragmentação florestal na Amazônia. Oecologia Brasiliensis, 13(3): 434-451.

Libardoni P, Atkinson R, Maurer S. 2007. A insustentabilidade humana e o desenvolvimento sustentável. Gaia Scientia, 1(2): 195-202.

Lopes A. 2016. O sobreaquecimento das cidades: Causas e medidas para a mitigação da ilha de calor de Lisboa. Territorium, (15): 39-52.

Maciel MNM, Watzawick LF, Schoeninger ER, Yamaji FM. 2003. Classificação ecológica das espécies arbóreas. Revista Acadêmica: Ciências agrárias e ambientais, 1(2): 69-78.

Magurran AE. 2006. Measuring biological diversity. Blackwell Publishing, 256p.

Martini AMZ, Jardim JG, Santos FAM. 2008. Floristic composition and growth habits of plants in understory, natural tree fall gaps, and fire-disturbed areas of a tropical forest in southern Bahia, Brazil. In: The Atlantic Coastal Forests of northeastern Brazil, p.147-192. McKinney ML. 2006. Urbanization as a major cause of biotic homogenization. Biological Conservation, 127 : 247-260.

Medeiros HR, Bochio GM, Ribeiro MC, Torezan JM, Anjos L. 2015. Combining plant and bird data increases the accuracy of an Index of Biotic Integrity to assess conservation levels of tropical forest fragments. Journal for Nature Conservation, (25): 1-7.

Medeiros HR, Torezan JM. 2012. Evaluating the ecological integrity of Atlantic Forest remnants by using rapid ecological assessment. Environ Monit Assess, 185: 4373-4382.

MMA - MINISTÉRIO DO MEIO AMBIENTE Plano de Manejo da Floresta Nacional de Ipanema, 2012. Disponível em: http://www.icmbio.gov.br/portal/images/stories/imgs-unidades-coservacao/flona ipanema. pdf Acesso em: 15 jan. 2016.

Pulighe G, Fava F, Lupia F. 2016. Insights and opportunities from mapping ecosystem services of urban green spaces and potentials in planning. Ecosystem Services, 22: 1-10.

Rocha ERS. 2013. Além do desenvolvimento sustentável: as sociedades sob a ótica da Ecologia Profunda. Gaia Scientia, 7(1): 9-22.

Salm R, Jardim MAG, Albernaz ALKM. 2011. Abundância e diversidade de palmeiras no Distrito Florestal Sustentável da rodovia BR-163, Pará, Brasil. Biota Neotropica, 11(3): 99-105. 
Santos SL. 2005. Dinâmica de clareiras: comportamento de espécies pioneiras e fatores que afetam sua colonização. Dissertação (Doutorado em Biologia Vegetal) - Universidade Estadual de Campinas, UNICAMP: Campinas.

Sayre R, Roca E, Sedaghatkish G, Young B, Keel S, Roca R. 2000. Nature in focus: Rapid ecological assessment. The Nature Conservancy, Washington: EUA, 182p.

Scoriza RN, Piña-Rodrigues FCM. 2013. Aporte de serapilheira como indicador ambiental em fragmentos de floresta estacional semidecidual em Sorocaba, SP. Revista Brasileira de Ciências Agrárias, 8(4): 634-640.

Simberloff D, Genovesi P, Pyšek P, Campbell K. 2011. Recognizing conservation success. Science, 332: 419_ 436.

Souza ACR, Almeida JR. EB, Zickel CS. 2009. Riqueza de espécies de sub-bosque em um fragmento florestal urbano. Biotemas, 22(3): 57-66.

Steenberg JWN, Millward AA, Duinker PN, Nowak DJ, Robinson PJ. 2015. Neighbourhood-scale urban forest ecosystem classification. Journal of Environmental Management 163: 134-145.

Wu J. 2010.Urban sustainability: an inevitable goal of landscape research. Landscape Ecology, (25): 1-4.

Wu M, Che Y, Yongpeng L, Yang K. 2017. Neighbourhood-scale urban riparian ecosystem classification. Ecological Indicators, (72): 330-339. 